DOI: $10.19275 /$ RSEP075

Received: 27.02 .2020

Accepted: 29.03 .2020

\title{
INVESTIGATING DE FACTO AND DE JURE EXCHANGE RATE REGIMES
}

\author{
Emmanuel Erem \\ Department of Economics, Maynooth University, Ireland. \\ emmanuel.erem.2018@mumail.ie
}

\begin{abstract}
Exchange rate regimes have evolved a lot of the years, specifically the past century, right from the Gold standard to the Bretton Woods era that led to the creation of the International Monetary Fund (IMF) and Post Bretton Woods periods that have seen the emergence of currency unions and a whole range of hybrid and more sophisticated exchange rate regimes. This evolution has led to the emergence of de jure and de facto exchange rate regimes. This discrepancy can be very misleading and pervasive for monetary policy and stability. In this paper, we combine an empirical econometric approach to develop an algorithm that will classify the de facto regimes that countries are practising by modelling exchange rate bands and the behaviour of a particular currency towards an anchor. The sample is representative of the globe. We believe the algorithm performs well and may be adopted by monetary authorities and international bodies like the International Monetary Fund.
\end{abstract}

Keywords: Exchange rate regime, algorithm

Jel Classification: F33

Citation: Erem. E. (2020). Investigating De Facto and De Jure Exchange Rate Regimes, Review of Socio-Economic Perspectives, Vol 5(1), pp. 35-60, DOI: 10.19275/RSEP075. 


\section{Introduction}

As stated by Svensson (1992), the exchange rate as conventionally defined is the domestic price of foreign exchange, that is, the number of domestic currency units per foreign currency unit. Generally, exchange rate regimes can be classified as fixed, floating and managed floating. Researchers have developed techniques that characterize the regimes based on certain variables and clustering the candidates for a certain regime accordingly. Their studies have resulted in classifications of up to ten or even more exchange rate regimes. It is thus the responsibility of the monetary authorities to deploy an exchange rate regime policy or mechanism that may seek to maintain this exchange rate or allow it more flexibility as and when they deem fit. The exchange rate regime employed by a country has macroeconomic effects on the economy through inflation, price, capital flows, economic growth and a number of other variables. Ghosh et al. (1997) shows that inflation is lower and more stable under the pegged regime and more pronounced output volatility. Some studies have linked the fixed exchange rate regime and/or monetary union to more growth, trade and less exchange rate volatility. Furthermore, Ghosh et al. (2015) show that macroeconomic vulnerabilities are significantly greater under less flexible regimes including hard pegs compared to floats. This is only a highlight of how important the regime employed by a country is for the economy as a whole.

In the integrated and globalised world of today, economies are intertwined thus the risk of financial and currency crises are very high and thus monetary policy management must consider effects of currency attacks and shocks coming from external sources. Ohno (1999) states that financial markets operate through expectations whose dynamics are not very well understood; this has come into surface as evidenced by the recent global financial crises. Exchange rates remain a pillar of macroeconomic stability and avoiding mis-valuation of a currency is an important step that is usually a predictor of an impending currency attack.

The main variables used in exchange rate classification are the exchange rate volatility, reserve volatility, interest rates and the behaviour of the exchange rate towards an anchor or reference currency. The more advanced economies especially those practising the inflation targeting mechanism have witnessed a drop in the exchange rate volatility over the years as opposed to the emerging market economies that have experienced more volatility and have more intervention in the markets. 


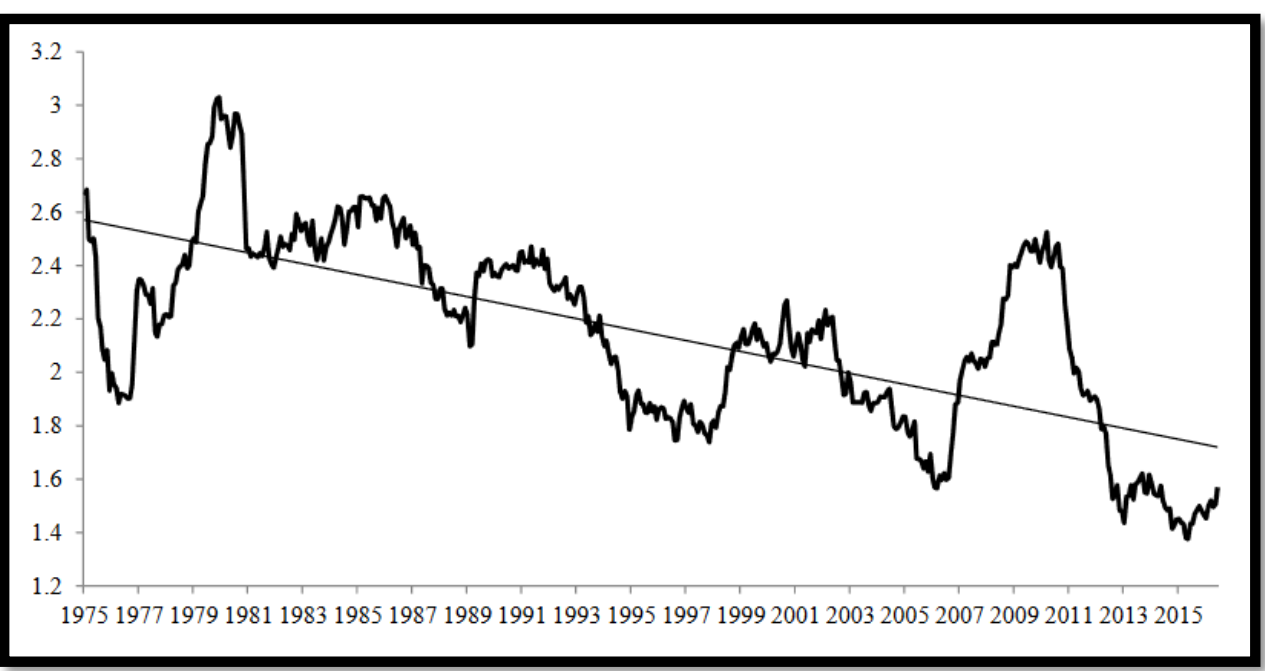

Source: Ilzetzki et al. 2017

A number of scholars have tried to classify the regimes being practised by countries and find a clear discrepancy in the de facto and de jure regimes. This discrepancy between the de facto exchange rate regimes, the regimes that countries actually follow and the de jure exchange rate regime, that is the regimes that countries claim to officially follow and report to the International Monetary Fund (IMF) and other similar institutions, can be very misleading and pervasive, this, according to Frankel and Wei (2008).

Ilzetzki et al. (2017) in their classification study of 195 countries (or territories) using monthly data on core exchange rate and inflation over the period 1946 to 2016, find that $80 \%$ of all countries covered are biased towards a less flexible exchange rate arrangement. They add that almost $40 \%$ of all countries under the inflation targeting framework adopt somewhat limited flexibility arrangements like crawling pegs. Thus, it is not right to assume that all inflation targeting countries adopt a floating regime. This is a re-enforcement of the same finding by Mishkin (2004). There is thus a markedly lower incidence of bi-polar or corner solutions; there is instead a marked increase in the adoption of intermediate regimes.

The evolving inconsistencies between the de facto and de jure exchange rate regimes have forced the IMF to move from a de jure classification that it focused on in the 1990s to an additional classification as well to avoid misalignment of monetary policy and economic decisions.

In this study, we develop a hybrid algorithm that combines within the band approach and a regression based approach to classify exchange rate regimes. The algorithm performs well and re-enforces and/or compliments the findings of previous Researchers. 


\section{Literature Review}

2.1 Brief History of the international monetary system

The classical gold standard (1870-1914)

Britain was the sole member at the beginning of this era, using gold as its trading currency, this forced her trading partners like Germany and the US to adopt this metallic standard currency form. By 1900, a number of countries had adopted gold as a form of exchange with only a few sticking to silver. Bordo (2003) adds that by 1900, most nations had switched away from silver and bimetallic standards and adhered to the gold standard. Fiat money and floating was considered to be a radical departure from fiscal and monetary stability and was only acceptable in case of global emergencies like wars and financial crises. Countries like Spain and Austria-Hungary that adopted fiat money and permanently floated were viewed with disfavour. Over this period, central banks were willing to convert paper currencies into a pre-determined amount of gold thus ensuring stable exchange rates in terms of gold. A country could not simply alter its money supply without experiencing gold flows since currencies were backed by gold. Sir John Swanwick Bradbury, a British Economist and official of the treasury in the 20th century put it, the gold standard was knave-proof characterised by low interest rates, price stability and increased world trade.

The gold standard collapsed in 1914 mainly due to World War I (1914-1918), countries needed a source to finance their war debts and gold was an inconvenience. In addition, this was a scarce metal. Governments resolved to printing more money and issuing bonds. There was a brief attempt by advanced economies to return to gold after the war but this was not fruitful. Britain attempted to return to the standard at the pre-war parity in 1925 in order to please its creditors and this left the Pound 10\% overvalued against the US Dollar due to the inflation gap since 1914. To a certain extent, the gold standard is blamed for the 1929 Wall Street crash.

Bretton Woods (1945-1971)

The agreement at Bretton Woods introduced a new era in monetary policy management. This resulted in the creation of the International Monetary Fund, the World Bank, the international gold-exchange standard and others. This was seen as an opportunity to correct the mistakes that led to the great depression of the 1930s and help rebuild after World War II (1939-1945). During this era, a number of countries pegged their currencies to the US dollar at specified parities, which in turn was convertible into gold at a fixed rate of $\$ 35 / \mathrm{oz}$; this characteristic defined the fixed exchange rate regime period preceding the 1970s. This only applied to Dollars held by central banks and Governments, not private persons. Central banks had to intervene in markets to fix their exchange rates against the Dollar, which in turn was pegged to gold. According to Bordo (2003), the agreement allowed narrow bands of $2.5 \%$ around parity and the right to change parity in the event of a fundamental misalignment thus fixed but adjustable. It was supposed to combine the advantages of the gold standard (sound money) with those of floating (flexibility and independence). The system was purposely meant to overcome the weaknesses characterised by the classical gold standard. A number of nations had difficulties in finding parities consistent with their balance of payment positions setting the stage for the collapse of the Bretton Woods. In addition, the re-alignment of parities 
led to a number of crises in the early years of the Bretton Woods system. The IMF was responsible for bailing out countries with balance of payments problems.

Demise of the Bretton Woods (1971-1973)

Like all economic systems, the Bretton Woods had its weaknesses, some of which led to its demise. The US was at the centre of the Bretton Woods given its large influence and dominance in international trade, gold stock and global finance. This influence inclined the US to run chronic trade deficits (that are still present today) allowing Americans to live beyond their means. A number of countries were angered by this and threatened to liquidate their Dollar reserve balances into gold. In addition, the US was characterised by high inflation rates in the 1960s due to the expansionary fiscal policy, something that a number of European countries feared would be imported into their economies. This was caused by the Dollar fight where a number of countries especially in Western Europe were converting their Dollars into gold. For fear of depletion of American gold, President Nixon closed the US Fed's gold window effectively suspending the commitment to provide gold to foreign central banks at any rate. Also, the demise of the Bretton Woods was caused by a failure by countries to find parity rates that are consistent with and favour balance of payments; this eventually led to the debate between the choice of a fixed or flexible regime.

According to Kawai and Akiyama (1998) in their account of the evolution of exchange rates, before the suspension of the convertibility of the US Dollar to gold by President Richard Nixon in 1971, exchange rate fluctuations of most IMF member countries had been limited to $+/-1 \%$ around par values set in terms of gold or the US Dollar. After the Nixon shock, these countries moved towards the floating exchange rate regime. The year 1973 saw the European Community countries sever the link between their currencies and the US Dollar. Some countries feared the risk of the true floating regime era and decided to maintain a peg to the currencies of major industrialised economies. Western European countries limited their exchange rate fluctuations within margins of $+/-2.25 \%$ with each other and a band of $4.5 \%$ against the Dollar. This was referred to as the 'snake regime', eventually forming the European Monetary System in 1979. This saw the emergence of the Deutschmark as the dominant currency in Europe and many countries began to mimic the monetary policies of the Bundesbank. Germany being the most stable and developed economy in the region made this inevitable; other countries in the region anchored their inflation rates to that of Germany which was the lowest in Europe. The French Franc also had considerable influence coupled with its CFA zone prevalently in West and Central Africa. Eventually these two blocks (Franc and DM) merged to form the Euro Area in 1999.

In the 1970s, the numeraire or reference currency which was the US Dollar was connected or linked to the supply and value of gold. Today, the numeraire is connected to the supply of US goods and services, in general terms, the performance and the value that the globe attaches to the US economy (fiat currency). There have been outcries from a number of nations both in emerging and advanced economies for a return to the Gold Standard based currency, a time of exchange rate stability and capital mobility, sacrificing monetary independence. It takes a lot for a shift in the international monetary system, sometimes a serious financial crisis or even a world war. However, it is hard to predict when the next shift shall come, thus we wait. 


\subsection{Classification of Exchange Rate Regimes}

Frankel (1992) pioneered a technique aimed at recovering the weights assigned to currencies in order to determine whether a regime is fixed or floating. This technique has been used and extended over the years and remains a very strong model till today.

Levy-Yeyati and Sturzenegger (2005) in their paper, Deeds vs Words, covering all IMFreporting countries over the period 1974-2000 revealed that pure floats are associated with minor nominal exchange rate volatility and that there has been an increase in the number of dirty floats over the years, supporting the fear of floating phenomenon. Furthermore, they point out that countries that appear to behave according to a de jure regime during tranquil times may be tempted to change their course of action once the regime is under stress. Levy-Yeyati and Sturzenegger (2016) extend their earlier studies through 2014 to cover the financial crisis period and increasing the sample size. They report that there was a growth in the number of floaters over the financial crisis period. Pegs remained the preferred regime for low income countries. Also, the number of countries which run a fixed regime without stating that they do (fear of pegging) has increased remarkably. Their findings further revealed that fixed regimes are characterized by relatively low nominal exchange rate volatility (with an average absolute change of $0.60 \%$ per month as opposed to $1.59 \%$ in the case of floats), and high volatility in reserves (19.15\% against $5.66 \%$ for floats).

Calvo and Reinhart (2002) using monthly data over the period 1970-1999 for 39 countries across all continents tried to compare what countries say and what they do, focussing on whether countries that claim to float are indeed doing so, whether countries are moving further towards corner solutions as they say. Analysing the behaviour of exchange rates, foreign exchange reserves and interest rates, they find that these countries had a volatility of these variables somewhat similar to those with a pegged regime. They show that the volatility in these variables of de jure floaters differs to a much greater extent from true floaters. Concluding that countries that say they allow their exchange rate to float mostly do not, there seems to be an epidemic case of fear of floating. Schnabl (2003) tries to replicate the technique identified by Calvo and Reinhart (2002) on Central and Eastern countries with some augmentations and finds that all the four countries in the study classified as fixed regimes show very low exchange rate volatility against the Euro and Dollar, particularly the Euro. And, among the de jure floaters, three countries pegged their currencies to the Euro.

Reinhart and Rogoff (2004), in a classification covering 153 countries over the period 1946-2001 that takes into account exchange rates in parallel markets has been used by a number of researchers in the areas of macroeconomics and finance. They develop an algorithm; in what they call a natural classification algorithm allowing for up to fourteen categories of exchange rate regimes ranging from a strict peg to a dysfunctional freely falling or hyper-float. Some of their findings revealed that de facto floating was common during the early years of the Bretton Woods era of fixed exchange regimes. Many de jure floats of the post 1980s turned out to be de facto pegs, crawling pegs or narrow bands to an anchor currency. Important to note in their findings, $53 \%$ of the countries listed in the IMF classification as managed floats turned out to be de facto pegs, crawls, or narrow bands to an anchor. 
According to Frankel (1999), most countries classified by the IMF as fixed regimes have in fact had re-alignments and most of those listed as floaters in fact intervene in the foreign exchange markets frequently.

Shambaugh (2004) while examining the effect of the fixed regime on monetary autonomy, uses a sample of over 100 developing and industrial countries from 1973 through 2000, creating a de facto coding system that focusses on the volatility of the exchange rate, dividing countries into pegs and non-pegs. He finds that his classification technique disagrees with the reported IMF de jure status about $12 \%$ of the time. He finds that most countries that claim to float do so to some degree and some are mislabelled.

Ghosh et al. (1997) in their investigation of whether the regime matters for macroeconomic performance, argue that the de jure classification captures the formal commitment of the central bank to intervene in the foreign exchange market while the de facto classification obviously has the advantage that it captures actual behaviour. They therefore adopt a technique that combines the de jure and de facto classifications in their study. They define a pegged regime as one with frequent and infrequent adjusters, the former being defined as regimes with more than one change per year in either parity or, for basket pegs, in the weights. They divide the regimes into three; pegged, intermediate and floating. They further find that a pegged regime is associated with lower inflation.

Kawai and Akiyama (1998) examining officially reported and empirically observed exchange rate arrangements of more than 100 countries over the period 1970-1996 find that most countries especially in Asia, Latin America and the Middle East attempt to peg their exchange rates particularly to the US Dollar, forming somewhat a Dollar block. The researchers further report that the role played by the Japanese Yen remains rather less significant.

Ilzetzki et al. (2017) in a comprehensive study of 194 countries over the period 19462016 state that the often-cited post-Bretton Woods transition from fixed to floating exchange rate regimes is overstated and emphasise that regimes with limited flexibility still remain preferred and in the majority. The US Dollar still scores as the world's dominant anchor currency and by a very large margin with a much wider use today than 70 years ago and the global role of the Euro seems to have stalled, may be for now. Some scholars argue that the world is headed towards a multi-polar system especially with the rise of China in the global economy, this will undermine the influence of the US Dollar and increase the weight of the Chinese Renminbi. Eichengreen (2011) re-iterates that it is very likely that the Euro will be the anchor currency in Europe, the US Dollar in the Americas leaving the emerging Renminbi anchoring in Asia, a role that the Japanese Yen has failed to take on to date. It is difficult to quantitatively disaggregate the influence of the Chinese Renminbi on its own since it has had a long history of being pegged to the US Dollar.

\subsection{The Choice of the Exchange Rate Regime}

The choice of an exchange rate regime may depend on a number of factors, some on the level of development of a country. Advanced economies literally have the capacity to defend their exchange rates against any speculative attack. Obstfeld and Rogoff (1995) add that if their commitment to use those resources lacks credibility with markets, the costs to the broader economy of defending a regime against speculative attacks could be 
very high. A major disadvantage of this regime is that the central bank loses control of domestic money supply thus monetary independence and cannot use monetary policy for stabilisation purposes in case of economic shocks.

Frankel (1999) classifies regimes as; Fixed arrangements (currency unions, currency boards and truly fixed arrangements), Intermediate arrangements (adjustable pegs, crawling pegs, basket pegs and target zones) and Floats (managed and free floats). Managed floats are also known as dirty floats defined as a readiness to intervene in the foreign exchange market, without defending any particular parity and most intervention is intended to lean against the wind; buying the currency when it is rising and selling when it is falling.

A number of countries especially emerging market economies are within the intermediate regimes like target zones and crawling pegs. According to Bordo (2003), exchange rate regimes have evolved a lot over the past 100 years; the advanced economies seem to get it right while the emerging markets try to emulate and may get the choice right occasionally. The regimes range from pure floats to the hard pegs of currency boards, dollarization and currency unions.

Of course, the regime employed by a country would also depend heavily on macroeconomic variables like inflation rates, reserves, financial market development and the general macroeconomic direction desired by the monetary authorities.

According to the IMF Annual Report on Exchange Rate Arrangements and Restrictions 2017, the de jure regimes are classified as indicated below;

No separate legal tender; The currency of another country may circulate as the sole legal tender. Some countries have become dollarized, substituting their currencies with the US Dollar, these include Ecuador and El Savador in Latin America and Zimbabwe in Africa. This form of arrangement involves the complete surrender of a nation's monetary policy independence. Currency unions for this matter are classified based on the arrangement governing the joint currency. The Euro for example is classified as a floating currency.

Currency Board; A currency board arrangement is a monetary arrangement based on an explicit legislative commitment to exchange domestic currency for a specified foreign currency at a fixed exchange rate, combined with restrictions on the issuing authority to ensure the fulfilment of its legal obligation. This implies that domestic currency is usually fully backed by foreign assets, eliminating traditional central bank functions such as monetary control and lender-of-last-resort and leaving little scope for discretionary monetary policy. According to Chang and Velasco (2000), under a currency board, the amount of base money in circulation is exactly equal to the foreign reserves of the central bank at all times. Hence there cannot be a balance of payments crisis. it stands ready to exchange Dollars for Pesos at a fixed exchange rate and, in addition, it is committed not to create or destroy Pesos in any other way.

Conventional Peg; The country formally pegs its currency at a fixed rate to another currency or basket of currencies, where the basket is formed, for example, from the currencies of major trading or financial partners and weights reflect the geographic distribution of trade, services, or capital flows. The anchor currency or basket weights are public or notified to the IMF. The country authorities stand ready to maintain the fixed parity through direct intervention (that is, via sale or purchase of foreign exchange 
in the market) or indirect intervention (for example, via exchange rate related use of interest rate policy, imposition of foreign exchange regulations, exercise of moral suasion that constrains foreign exchange activity, or intervention by other public institutions). There is no commitment to irrevocably keep the parity. the exchange rate may fluctuate within narrow margins of less than \pm 1 percent around a central rate or the maximum and minimum value of the spot market exchange rate must remain within a narrow margin of 2 percent for at least six months.

Stabilized Arrangement; This entails a spot market exchange rate that remains within a margin of 2 percent for six months or more (with the exception of a specified number of outliers or step adjustments) and is not floating. The required margin of stability can be met either with respect to a single currency or a basket of currencies, where the anchor currency or the basket is ascertained or confirmed using statistical techniques. Classification as a stabilized arrangement requires that the statistical criteria are met and that the exchange rate remains stable as a result of official action (including structural market rigidities). The classification does not imply a policy commitment on the part of the country authorities.

Crawling Peg; The currency is adjusted in small amounts at a fixed rate or in response to changes in selected quantitative indicators, such as past inflation differentials vis-à-vis major trading partners or differentials between the inflation target and expected inflation in major trading partners. The rate of crawl can be set to generate inflation-adjusted changes in the exchange rate (backward looking) or set at a predetermined fixed rate and/or below the projected inflation differentials (forward looking). The rules and parameters of the arrangement are public or notified to the IMF. Obstfeld and Rogoff (1995) state that the crawling peg is common among high-inflation developing countries in which the Government announces a schedule of small, discrete devaluations in order to prevent inflation differentials from cumulating, thereby necessitating a single large devaluation.

Crawl-like Arrangement; The exchange rate must remain within a narrow margin of 2 percent relative to a statistically identified trend for six months or more (with the exception of a specified number of outliers) and the exchange rate arrangement cannot be considered as floating. Normally, a minimum rate of change greater than allowed under a stabilized (peg-like) arrangement is required. However, an arrangement will be considered crawl-like with an annualized rate of change of at least 1 percent, provided that the exchange rate appreciates or depreciates in a sufficiently monotonic and continuous manner.

Pegged exchange rate within horizontal bands; This involves the confirmation of the country authorities' de jure exchange rate arrangement. The value of the currency is maintained within certain margins of fluctuation of at least \pm 1 percent around a fixed central rate, or the margin between the maximum and minimum value of the exchange rate. It includes arrangements of countries in the ERM of the European Monetary System (EMS), which was replaced with the ERM II on January 1, 1999, for those countries with margins of fluctuation wider than \pm 1 percent. The central rate and width of the band are public or notified to the IMF. 
Other managed arrangement; This category is a residual and is used when the exchange rate arrangement does not meet the criteria for any of the other categories. Arrangements characterized by frequent shifts in policies may fall into this category.

Floating; A floating exchange rate is largely market determined, without an ascertainable or predictable path for the rate. In particular, an exchange rate that satisfies the statistical criteria for a stabilized or a crawl-like arrangement will be classified as such unless it is clear that the stability of the exchange rate is not the result of official actions. Foreign exchange market intervention may be either direct or indirect, and such intervention serves to moderate the rate of change and prevent undue fluctuations in the exchange rate, but policies targeting a specific level of the exchange rate are incompatible with floating. Indicators for managing the rate are broadly judgmental (for example, balance of payments position, international reserves, parallel market developments). Floating arrangements may exhibit more or less exchange rate volatility, depending on the size of the shocks affecting the economy.

Free Floating; A floating exchange rate can be classified as free floating if intervention occurs only exceptionally and aims to address disorderly market conditions and if the authorities have provided information or data confirming that intervention has been limited to at most three instances in the previous six months, each lasting no more than three business days. If the information or data required are not available to the IMF, the arrangement will be classified as floating. Detailed data on intervention or official foreign exchange transactions will not be requested routinely from member countries, but only when other information available to the IMF is insufficient to resolve uncertainties about the appropriate classification.

Monetary Policy Framework

Also according to the IMF, the monetary policy frameworks employed by central banks are as follows;

Exchange rate anchor; The monetary authority buys or sells foreign exchange to maintain the exchange rate at its predetermined level or within a range. The exchange rate thus serves as the nominal anchor or intermediate target of monetary policy. These frameworks are associated with exchange rate arrangements with no separate legal tender, currency board arrangements, pegs (or stabilized arrangements) with or without bands, crawling pegs (or crawl-like arrangements), and other managed arrangements. Common anchor currencies include the US Dollar, Euro or a composite consisting of two or more currencies as an anchor.

Monetary aggregate target; The intermediate target of monetary policy is a monetary aggregate such as M0, M1, or M2, although the country may also set targets for inflation. The central bank may use a quantity (central bank reserves or base money) or price variable (policy rate) as an operational target.

Inflation-targeting framework; This involves the public announcement of numerical targets for inflation, with an institutional commitment by the monetary authority to achieve these targets, typically over a medium-term horizon. Additional key features normally include increased communication with the public and the markets about the plans and objectives of monetary policymakers and increased accountability of the central bank for achieving its inflation objectives. Monetary policy decisions are often 
guided by the deviation of forecasts of future inflation from the announced inflation target, with the inflation forecast acting (implicitly or explicitly) as the intermediate target of monetary policy.

\subsection{Within the Band Regimes}

Krugman (1991), using a basic monetary model, developed an elegant fundamental model of exchange rate behaviour under a target zone exchange rate regime. The main result shows that the expectation that monetary policy will be adjusted to limit exchange rate fluctuation affects the exchange rate behaviour even when the exchange rate lies inside the target zone and is thus not being defended actively. Most scholars have provided a modification or an extension of this model one way or the other. A target zone should not be confused with a fixed exchange rate regime; a target zone may allow the exchange rate to fluctuate around a fairly wide predetermined reference rate. It could be $10 \%$ or any other reasonable rate on either side of the central rate. It is argued that countries may adopt a target zone regime since it does not require a lot of monetary policy action compared to the strictly pegged regime whose defence is a full time job.

The Krugman (1991) model is based on two critical assumptions; the target zone is perfectly credible, market agents believe the lower and upper edges of the band will remain fixed forever and the exchange rate will forever stay within the band. Secondly, the exchange rate is defended with minimal interventions by the monetary authorities, money supply remains constant and no interventions as long as the exchange rate remains within the band. These assumptions are re-iterated by Svensson (1992).

Figure 2: The Krugman model of exchange rate target zones

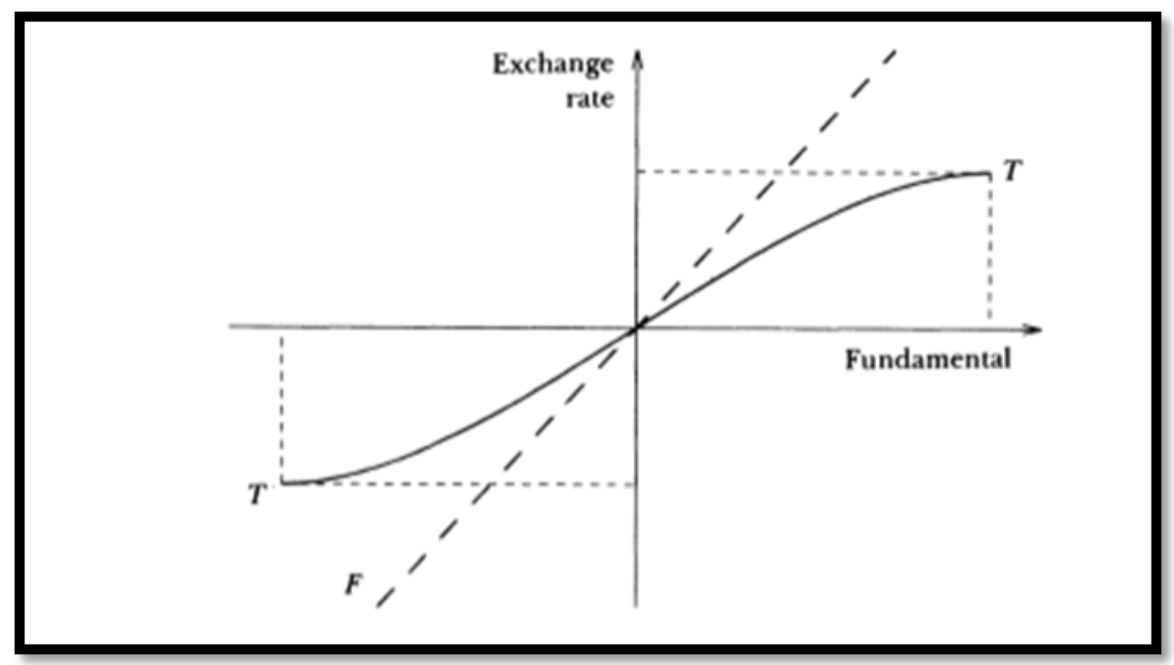

Source: Svensson (1992)

The model predicts the S-shape non-linear relationship between the exchange rate and its fundamental determinants as shown by the curve TT. The line F represents the equilibrium exchange rate in the free-floating regime. The assumption is that the exchange rate depends linearly on macroeconomic fundamental and the expected future 
value of a currency. Within the fundamental, there are two components, that is, velocity and domestic money supply where velocity is exogenous and stochastic while the money supply is changed or altered by the central bank from time to time to control and manage the exchange rate. As long as the exchange rate lies within the band, the money supply remains unchanged. The stochastic process is assumed to follow a Brownian motion without drift. The main results from the Krugman model are the honeymoon effect and smooth pasting. As revealed in literature by Svensson (1992), if the exchange rate is higher and closer to the upper edge of the exchange rate band, the probability that it will reach the upper edge is higher. Thus, the probability that there will be future intervention to reduce money supply and strengthen the currency is higher. The target zone exchange rate is less than the free-float exchange rate for a certain level of the fundamental. He further adds that the slope of the target zone exchange rate function is zero at the edges of the band thus the exchange rate at this point is insensitive to changes in the fundamental; this is smooth pasting. The honeymoon effect implies that a perfectly credible target zone has the stabilization effect and smooth pasting implies the exchange rate is a non-linear function of is fundamental determinants and insensitive to these fundamentals at the edge of the exchange rate band.

A further concept to the target zone literature is the time varying re-alignment risk which occurs when the exchange rate band is allowed to shift over a period. Bertola and Svensson (1993) pioneered interest in this area and were the first to present an exchange rate target zone model with time varying re-alignment risk. The introduction of time varying re-alignment risk changes the process by which the interest rate differentials are determined and the interpretation of interest rate differentials against exchange rate plots. The interest rate differential is now equal to the sum of the expected rate of currency depreciation within the band and the expected rate of re-alignment. The diagram shows the log of the French Franc/Deutschemark exchange rate from the start of the European Monetary System in March 1973 through to 1992 with a band of $+/-2.25 \%$ around a central rate. There were re-alignment shifts in September 1979, October 1981, June 1982, March 1983, April 1986 and January 1987 with the Franc being devalued against the Mark, that is, the number of francs per mark increased.

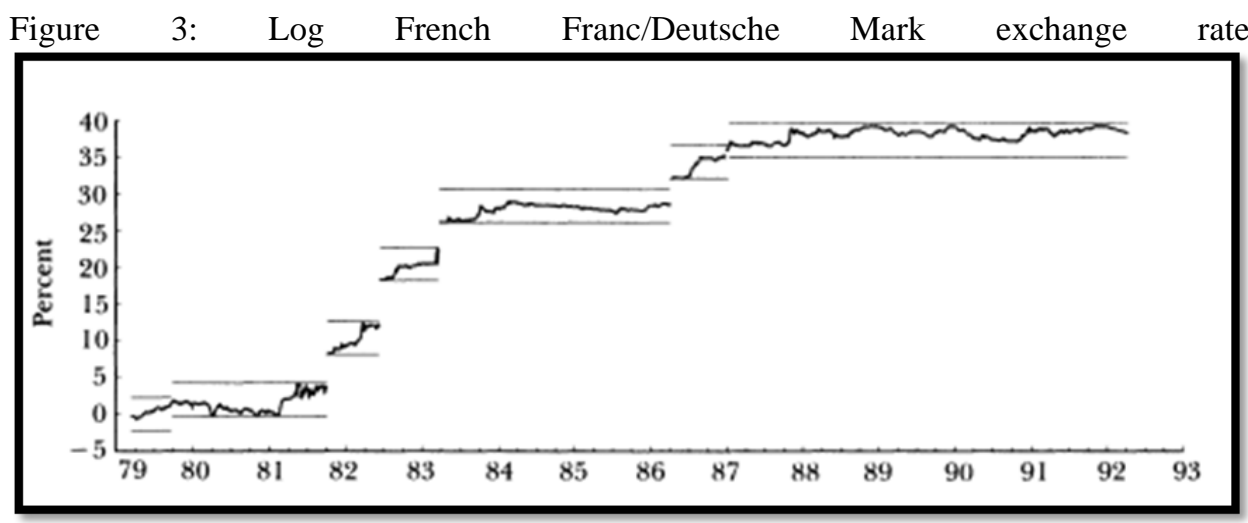

Source: Svensson (1992) 
Hurley et al. (1993) in their study of the appropriate level of required to defend an exchange rate target zone found that; for the case of Ireland, reserves were approximately optimal for most of the 1980s but significantly below optimal during 1989 and 1992. Furthermore, the authors concluded that foreign exchange reserves should at least be kept above $25 \%$ of domestic credit.

\subsection{Optimal Currency Area (OCA)}

Frankel (1999) defines an optimum currency area as a region for which it is optimal to have its own currency and its own monetary policy. Mundell (1961) defines an OCA as a currency area for which the costs of relinquishing the exchange rate an internal instrument of adjustment (within the area) are outweighed by the benefits of adopting a single currency or a fixed exchange rate regime. The registered success of the Eurozone has of recent re-ignited studies in the optimum currency area and its applicability. Fleming (1971) and Ricci (2008) stress that the similarity of pre-union inflation rates across countries may be considered as an important factor determining the OCA Countries may have different Phillips curves and thus by imposing a unique level of inflation by adopting a common currency will automatically generate some costs. The OCA theory was fast put forward by Mundell (1961) where he develops a simple twoentity model which could be regions or countries initially at full employment and balance of payments equilibrium and introduces asymmetric shocks to output and an adjustment mechanism. He asks the question whether countries intending to form common markets and economic unions should allow each of their national currencies to fluctuate or form a single currency area. He argues that the subject of flexible exchange rates can be separated into two distinct questions. The first is whether a system of flexible exchange rates can work effectively and efficiently in the modern world economy. For this to be answered, it must be demonstrated that: (1) an international price system based on flexible exchange rates is dynamically stable after taking speculative demands into account; (2) the exchange rate changes necessary to eliminate normal disturbances to dynamic equilibrium are not so large as to cause violent and reversible shifts between export and import-competing industries; (3) the risks created by variable exchange rates can be covered at reasonable costs in the forward markets; (4) central banks will refrain from monopolistic speculation; (5) monetary discipline will be maintained by the unfavourable political consequences of continuing depreciation, as it is to some extent maintained today by threats to the levels of foreign exchange reserves; (6) reasonable protection of debtors and creditors can be assured to maintain an increasing flow of long-term capital movements and (7) wages and profits are not tied to a price index in which import goods are heavily weighted. The second question he answers is how the world should be divided into currency areas; the stabilization argument for flexible exchange rates is valid only if it is based on regional currency areas. If the world can be divided into regions within each of which there is factor mobility and between which there is factor immobility, then each of these regions should have a separate currency which fluctuates relative to all other currencies. This carries the argument for flexible exchange rates to its logical conclusion. However, if labour and capital are insufficiently mobile within a country then flexibility of the external price of the national currency cannot be expected to perform the stabilization function attributed to it, and one could expect varying rates of unemployment or inflation in the different regions. A key weakness of the Mundell (1961) model is that he assumed that economic 
agents did not incorporate expectations about future movements in the price level, interest rates, exchange rates and Government policy.

Symmetry in business cycles has been put forward by some scholars as a condition for the OCA. Symmetry in the business cycle is defined as a positive co-movement between the two countries' output; the shocks or disturbances affect the countries in a much similar way thus symmetric. The existence of highly correlated business cycles is a signal that the two countries can almost form an OCA with a common monetary policy. Asymmetric shocks on the other hand tend to come along with inflationary pressures for the country that has gained from this sort of shock, monetary expansion is still possible though. Asymmetric shocks are caused by differences in financial and tax systems, structural differences in labour markets and institutions. Shocks could come from shifts in demand as described in the model by Mundell (1961). It is important to note that the actions of monetary policy have an effect on the exchange rates if not handled carefully (appreciation and depreciation). In relation to this, Ricci (2008) states that the exchange rate between two areas is an effective instrument of short-run adjustment if the following conditions hold; (1) the two areas face asymmetric shocks, so that an adjustment of the relative price of the goods produced in the two countries is required; (2) domestic prices are not fully flexible that is prices do not adjust immediately to shocks (price stickiness); (3) pass-through is not large therefore a relative price change due to exchange rate change is not immediately neutralised by domestic price movements.

Bayoumi and Eichengreen (1998) in a study that takes into consideration the exchange rate regimes employed by the advanced economies find that the OCA variables have an explanatory power towards the variations in exchange market pressures and thus exchange rate behaviour. The OCA variables affect the bilateral exchange rates through market conditions and intervention with asymmetric shocks being the main source of exchange market pressures and proxies for deterioration in the transactions value of money due to floating provide the main motivation for intervention.

2.6 Why countries float or peg and anchor currencies

Levy-Yeyati and Sturzenegger (2005) findings support the fact that countries may declare a regime and behave differently in order to avoid speculative attacks on their currencies. In this regard, fixers may declare a more flexible regime, the concept of hidden pegs. Their findings further reveal that intermediate regimes like crawling pegs and bands have reduced in number over the years. Furthermore, they find that de facto floats are characterized by small amounts of exchange rate variability thus a large number of these countries intervene in the markets in order to maintain a certain exchange rate. This is in opposition to the textbook definition of a floating regime, confirming the concept of fear of floating introduced by Calvo and Reinhart (2002).

Ilzetzki (2017) emphasize that the reserve currency composition is a good indicator of whether a country may be inclined to intervening in the markets to defend its exchange rate value against the currency whose share of the reserve composition is higher. For instance, if the euro takes a bigger share of the reserve composition in relation to other currencies, this country is likely to choose the euro as an anchor. The historical colonial relationship between two countries may also play a part when it comes to choosing an anchor currency. By default, emerging economies are to a greater extent peg their currencies to that of their colonial masters. Countries facing macroeconomic instabilities 
like high inflation rates tend to choose as an anchor the currency of a country whose performance they want to mimic.

Many scholars have argued that a fixed exchange rate regime is associated with less exchange rate volatility and thus likely to increase trade. A country whose foreign trade is mostly with Eurozone countries and invoices in Euros is likely to deploy the Euro as an anchor currency. Mussa (1986) argues that the real exchange rates show greater volatility under floating regimes than they do under the fixed regime. Kenen and Rodrik (1986) argue that the volatility of the real exchange rate depresses trade and thus a fixed regime is pro-trade. Aristotelous (2001) contradicts this result and reveals that the regime employed by a country has no effect on the export volume. Bacchetta and Van Wincoop (2000) introduce a new perspective altogether, adding that, adopting a fixed regime does not necessarily lead to more trade, the volume of trade will depend on how the regime is implemented. Rose (2000) argues that countries in a currency union trade more with each other than they do with countries outside a union, approximately 3.35 times more with each other. This finding is further supported by Adam and Cobham (2007).

Under The Maastricht Treaty signed in 1992 by members of the European Community to further European integration, countries within the union and candidates to adopt the Euro currency are required to peg their currencies to the Euro over a band for a period of at least 2 years. This pegging enables the EU gain a credible mechanism for evaluating potential Eurozone members. The Danish Krone is the only currency in the ERM II stage, thus pegging its exchange rate to the Euro. According to the European Central Bank, the Danish Krone fluctuates within a band of $+/-2.25 \%$ against the Euro. However, the standard ERM II fluctuation band is $+/-15 \%$. This inconsistency is simply because of the existence of an already high degree of convergence of the Danish Krone against the Euro.

Figure 4: Exchange rate of the Krone/Euro

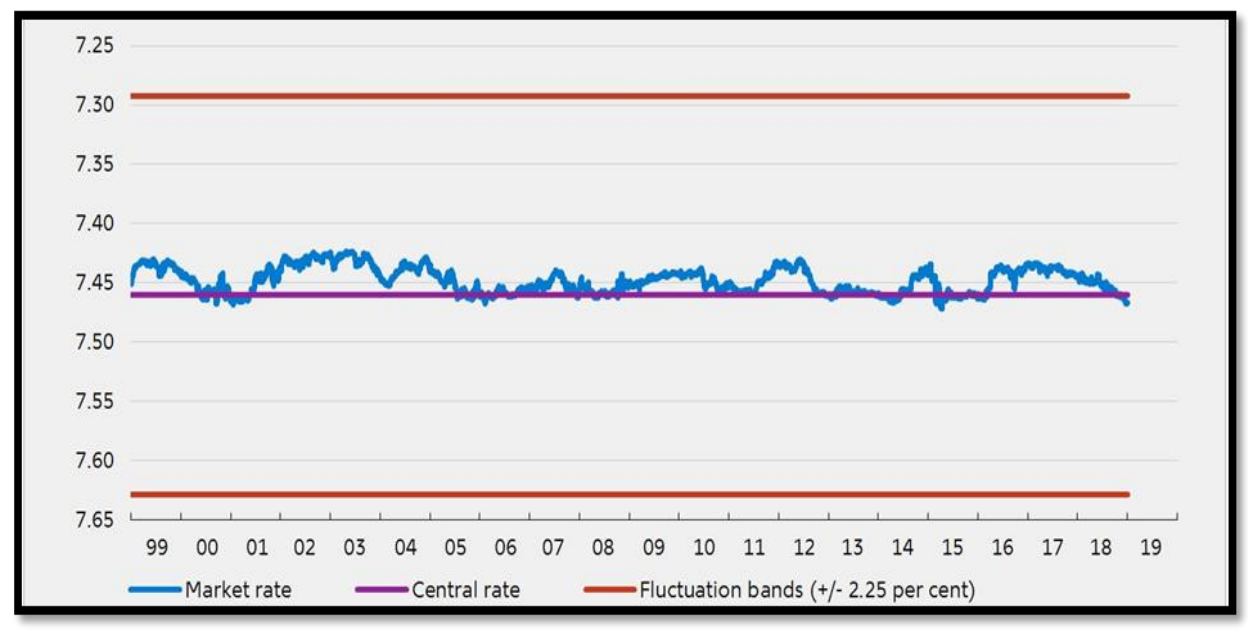

Source: Danmarks Nationalbank 
A number of countries have foreign currency denominated debt in anchor currencies like the US Dollar and Euro, thus, find it wise to peg to these currencies and avoid destabilising fluctuations while it services its foreign debt.

Theoretical grounding reveals that the floating exchange rate regime acts as a shock absorber to internal and foreign macroeconomic shocks, enabling the economy to adjust accordingly by adjusting interest rates, this with the assumption of capital mobility. These could include inflationary shocks, financial crises, commodity price shocks and business cycles with booms and depressions (output or unemployment shocks). Fixed exchange rate regimes are linked to financial crises since the monetary authorities have to constantly defend the exchange rate regime which may not be possible at times due to inadequate reserves and underdeveloped capital markets. This was evident during the Asian financial crisis of 1997, the Mexican crisis of 1995 and the Russian crisis of 1997. McKinnon (2000) uses high frequency (daily) data to test for the weight of the Dollar versus the Yen and notes in his study that by keying to the Dollar, the macroeconomic policies of the Asian crisis economies were loosely tied to each other. Some of the countries affected by the 1997 crisis subsequently switched to an inflation targeting regime that is primarily characterised by a floating exchange rate regime. Baig (2001) in a study examining the daily exchange rate behaviour of 5 East Asian currencies before, during and after the Asian crisis of 1997 found that these countries maintained a de facto peg to the US Dollar over the pre-crisis period, however, he adds that this result may not be reliable given that the results from the regressions of de jure floaters or the control group exhibited large and significant coefficients similar to those of the Asian crisis countries. Mishkin (2004) points out that countries employing inflation targeting as a monetary policy framework are not necessarily targeting only inflation but the exchange rate as well thereby intervening in the foreign exchange markets to defend a regime, an act that contradicts the inflation targeting model.

The pegged system especially to a recognised anchor currency like the US Dollar is a good practise to attract foreign investors, investors are able to evaluate their returns on investment over time easily with less fluctuations. In addition, the currency that comprises the biggest percentage of a country's reserves is a good indicator that the country in question pegs its exchange rate to that currency. Pegging to low inflation currency has the advantage of reducing domestic inflation pressures.

\subsection{Regimes and Crises}

According to Calvo and Mishkin (2003), a number of countries choose an intermediate path when it comes to exchange rate regimes; that is an exchange rate is often stabilized by the central bank, but might sometimes shift, often known as a "soft peg." However, in the aftermath of the macroeconomic crisis across East Asia in 1997-1998, a view emerged that this exchange rate regime was in part responsible for the depth of the macroeconomic crisis. The governments of Thailand, Malaysia, South Korea and other nations in that region had kept exchange rates fixed, closely following the US Dollar. Frankel (1999) argues that contrary to what is always claimed that Mexico, Thailand, Indonesia, Korea, Russia or Brazil were formally pegged to the dollar when their crises hit, they actually were following varieties of bands, baskets, and crawling pegs. This remains open to debate as other scholars have found a rather different result. 
Chang and Velasco (2000) provide a detailed and impressive model of the relationship between financial fragility and the exchange rate regime, comparing currency boards, fixed rates, and flexible rates, with and without a lender of last resort. They note that under a currency board the exchange rate is fixed and the central bank does not issue domestic credit and thus is vulnerable to bank runs and not currency crises. A fixed exchange rate regime is more prone to bank runs, exchange rate crises and balance of payments crises. A flexible rate system implements the social optimum and eliminates runs, provided that the exchange rate and credit policies of the central bank are appropriately designed. They argue that the abilities of the currency boards have been observed in the successes registered by Hong Kong and Argentina over a turbulent period in the recent past when financial institutions came under intense pressures globally.

Aghion et al. (2001) while developing a model of currency crises driven by the interplay between the credit constraints of private domestic firms and the existence of nominal price rigidities and examining the impact of various shocks including expectations shocks, argue that currency crises can occur under both the fixed and flexible exchange rate regime since the primary source of the currency crisis is identified as the deteriorating balance sheet of private firms. They add that an initial regime may be able to maintain a stable exchange rate when the economy is hit my small shocks, however, if the shock is large, then the initial regime has little influence in preventing a currency crisis. The regime employed thus becomes irrelevant.

Haile and Pozo (2006), using a broad sample of 35 countries, test whether the exchange rate regime employed by a country has an impact on the vulnerability of the countries to currency crisis using an extreme value theory technique, constructing an exchange market pressure index and a Hill Estimator/Tail Index to identify exchange market crises. The index is constructed as the weighted average of nominal exchange rate depreciation, change in domestic and foreign interest rates differential and decrease in foreign exchange reserves. In their words, "we find that the actual or de facto exchange regime plays no role in determining currency crisis periods. Fundamentals and contagion instead appear to be the main determinants of currency crises. We find, however, that while the de facto exchange regime fails to explain currency crises, the declared exchange regime does play a role with declared pegs increasing the likelihood that a nation experiences a currency crisis. Our results are consistent with the idea that soft pegs are easy targets for speculators and as such have a higher probability of resulting in a currency crisis with the peg turning into a float.'

Calvo and Mishkin (2003) state that one danger of a hard exchange rate peg is the risk of being locked into a misaligned exchange rate, defined as a sizable difference between its actual level and the one which fundamentals would dictate. They further note that neither the fixed nor the freely floating regimes has an unblemished record with regard to crises and that no exchange rate regime can prevent macroeconomic turbulence. The choice of the regime should be chosen to match the characteristics of the economy in question. The authors state in their paper that the regime chosen is of second-order importance. Of primary importance is the need for reforms; more regulation for the financial sector, fiscal constraint and developing a predictable monetary policy and more trade openness, these reforms will help emerging market economies be more immune to currency crises. 


\subsection{The testing, estimation and classification models}

Frankel (1992), Frankel and Wei (1994), Ohno (1999) and McKinnon (2000) use a technique that recovers the weights that countries assign to certain anchor currencies or currency baskets, containing currencies that countries may claim to peg to. If the weight assigned to an anchor currency is close to one, then a peg or fixed regime is identified. In all studies, the researchers find that the coefficients estimated for the Asian economies are close to one for the US Dollar indicating a close peg. Ohno (1999) extends and/or modifies this technique by incorporating the real effective exchange rate and using simulations, constructing multiple currency baskets containing currencies of three industrial blocks, that is, Yen, US Dollar and Euro. He adds that there is a high risk associated with using high frequency data when evaluating exchange rate performance. He finds that there were no risky pre-crisis exchange rate misalignments among the worst hit countries of the 1997 Asian crisis.

As earlier stated Calvo and Reinhart (2002) test for the de facto exchange rate regimes using three criteria; monthly percentage exchange rate changes, monthly percentage changes of official foreign reserves and monthly absolute changes in nominal short-term interest rate, estimating the probability that a variable falls within a predetermined bound that defines a certain exchange rate regime. For instance, if a bound is set at $2.5 \%$ then the probability that the monthly exchange rate change falls within the $2.5 \%$ band will be greatest for the fixed regime and lowest for the freely floating regime. They follow the same procedure to examine the behaviour of reserves and interest rates that are used by Governments as monetary policy tools.

Levy-Yeyati and Sturzenegger $(2005,2016)$ define exchange rate regimes according to the behaviour of three variables; changes in the nominal exchange rate, volatility of these changes and the volatility of international reserves. Fixed exchange rate regimes are characterised by more changes in international reserves aimed at reducing the volatility in the nominal exchange rate, and flexible regimes are characterized by substantial volatility in nominal rates with relatively stable reserves. The researchers develop clusters, the clusters with high volatility of reserves and low volatility of nominal exchange rate are fixers while those with low volatility in international reserves and substantial volatility in the nominal exchange rate identify as flexible. They note that reserves are notoriously hard to measure and there is a large difference between changes in reserves and interventions. Their approach uses a cluster analysis to identify the exchange rate regimes based on the classification variables. This is a multivariate approach used to identify homogeneous observations, according to similarities between data points along certain identified dimensions.

Ilzetzki et al. (2017) stress that any classification algorithm must simultaneously determine both an anchor currency, if any, and its degree of fixity or flexibility. They go ahead and develop an anchor or reference currency classification algorithm emphasizing that this can prove to be a heavy task given that there is a great degree of flexibility in exchange rates globally and some anchor or reference currencies may not be declared by monetary authorities.

Frankel and Wei (2008) propose an extension to the original regression based technique that incorporates an exchange market pressure variable defined as a percentage increase in the value of the currency plus the percentage increase in reserves. This answers the 
question as to what extent the authorities allow the increase in international demand for a currency to show up as an appreciation in the currency and to what extent as an increase in reserves.

\section{The Model}

We construct a $+/-2.5 \%$ for our local currency of interest against the four chosen anchors in our study to determine the extent to which the probability of the jumps against these anchor currencies are within this chosen band. A high probability within the band against a particular anchor is a sign of pegging. According to Ilzetzki (2017) and by intuition, the chosen anchor currencies display a much tighter link and less variation to the currency of the country under scrutiny than other potential anchors, that is to say less volatility.

We apply the regression in equation 1 below, and further augment it with a market pressure variable, defined in equation 2

$\Delta \operatorname{Ln}\left(\frac{L C Y}{C H F}\right)_{t}=\beta_{1}+\beta_{2} \Delta \operatorname{Ln}\left(\frac{U S D}{C H F}\right)_{t}+\beta_{3} \Delta \operatorname{Ln}\left(\frac{E U R}{C H F}\right)_{t}+\beta_{4} \Delta \operatorname{Ln}\left(\frac{J P Y}{C H F}\right)_{t}+\beta_{5} \Delta \operatorname{Ln}\left(\frac{G B P}{C H F}\right)_{t}+\varepsilon_{t} \ldots \ldots \ldots 1$

$\Delta \operatorname{LnMP}_{t}=\Delta \operatorname{LnRes}_{t} \Delta \operatorname{Lni}_{t}$

Where LCY is the domestic currency of the country under study, USD is the US Dollar, EUR is the Euro, JPY is the Japanese Yen, GBP is the British Pound and finally CHF is the Swiss Franc, the numeraire. Furthermore, MP, Res,and i represent the Market Pressure, Reserves and Interest rate respectively. The technique aims to recover the weights, $\beta \mathrm{s}$, that are assigned by each country to the potential anchor currencies. A $\beta$ close to one and statistically significant shows a sign of pegging and a $\beta$ close to zero and not significant is a sign of a floating regime.

With these regressions in mind, we further break down the data into sup-periods, that is, pre-crisis, crisis and post crisis periods to check whether the regime is switching between anchors. 
Given the previous discussions, we move further and develop the classification algorithm shown below.

Figure 5: The Algorithm

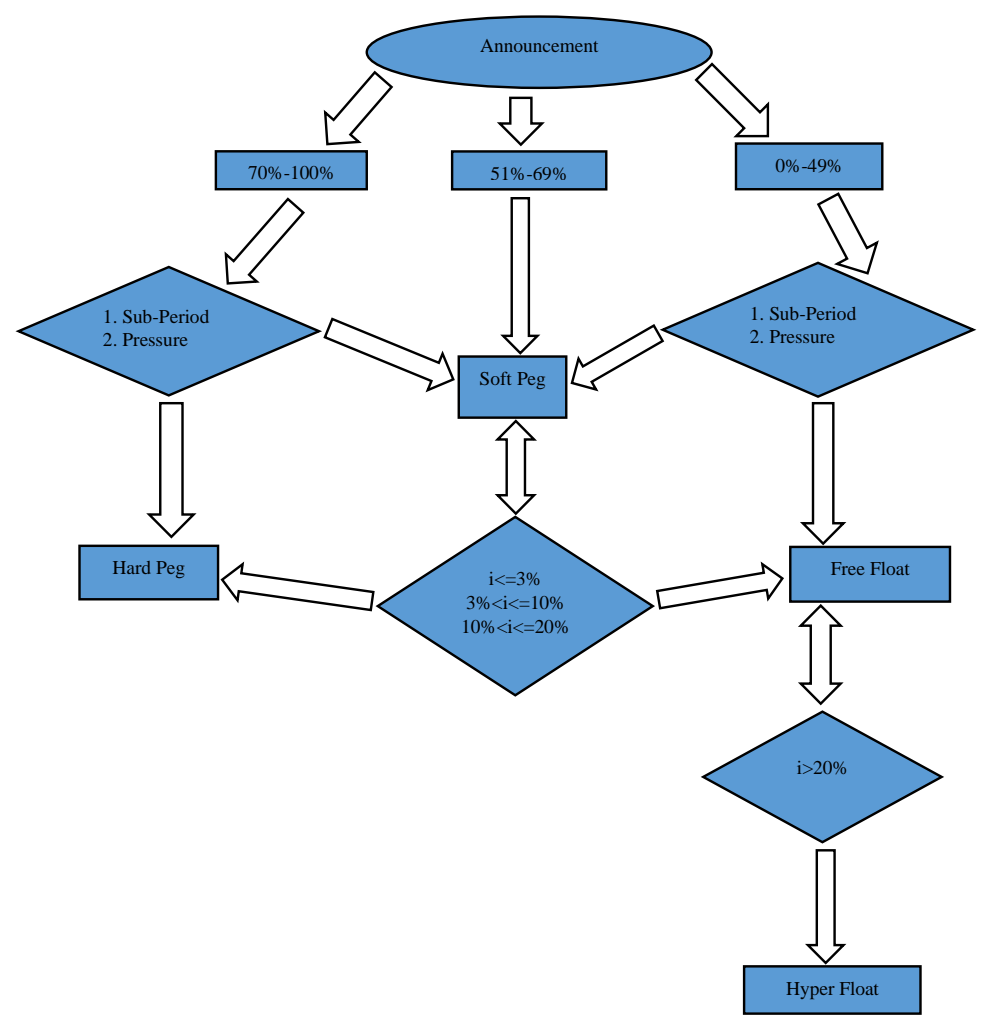

The algorithm is briefly described as follows; (1) Apply the $+/-2.5 \%$ band to discern categorise regimes as hard pegs, softs pegs and floats. (2) Ask the questions whether the regime is responding to the Market Pressure variable and switching between anchors. If the answer is yes to both then the regime qualifies to take the free float route and if the answer is no to both then the regime qualifies to take the hard peg route. If the regime fails either one or both criterion at this stage, then it takes the soft peg route where it is then subjected to an inflation(i) test. (3) $\mathrm{i}<=3 \%$ (Hard Peg), 3\%<i<=10\% (Soft Peg), $10 \%<\mathrm{i}<=20 \%$ (Free Float) and $\mathrm{i}>20 \%$ (Hyper Float).

It is important to note that a different category of strictly pegged regimes are identified by simply running equation 1 and if the weight on the preferred anchor is equal to 1 then this currency is exactly tracking the chosen anchor at each and every time period.

Monthly data on 70 countries to best represent the globe is collected. These countries are; Europe; Albania, Armenia, Bulgaria, Czech Republic, Denmark, Hungary, Iceland, Norway, Poland, Romania, Russia, Sweden, Turkey and Ukraine. 
Americas; Argentina, Aruba, Barbados, Bahamas, Brazil, Canada, Chile, Colombia, Jamaica and Mexico

Asia and Middle East; Bahrain, China, Hong Kong, India, Israel, Malaysia, Oman, Philippines, Qatar, Saudi Arabia, Singapore, South Korea, Thailand and United Arab Emirates.

Oceania; Australia, Fiji and New Zealand.

Africa; Algeria, Benin, Burkina Faso, Cameroon, Central African Republic, Chad, Congo, Côte d'Ivoire, Egypt, Equatorial Guinea, Eritrea, Ethiopia, Gabon, Ghana, Guinea-Bissau, Kenya, Mali, Morocco, Niger, Nigeria, Rwanda, Senegal, Seychelles, South Africa, Tanzania, Togo, Tunisia, Uganda and Zambia.

It is tempting to use the Chinese Renminbi as a possible anchor currency in equation 1 given its recent inclusion to the SDR basket and increased share in global GDP, however, this will not be a good idea given that it has for a long period of time been known to be pegged to the US dollar and this would obscure or confound to a great extent the integrity of the findings of this study.

We use the Swiss franc as a numeraire currency to express the value of all currencies in terms of a common currency. The Swiss Franc is our preferred choice because it is a freely floating currency of an advanced economy. In addition, the volume of trade between Switzerland and the countries chosen in the sample is quite minimal. A significant volume of trade would encourage pegging to reduce the exchange rate risk associated with exchange rate fluctuations.

Furthermore, the Swiss Franc is considered a safe haven currency. The stability of the Swiss Government, sound macroeconomic stability and developed financial system makes it a good candidate as a numeraire. Switzerland is independent of the European Union, to a greater extent, this shields the country from negative occurrences and pressures from the EU and Euro area. However, the currency periodically faces an upward pressure due to increased demand given that it's a safe haven; this could result in an overvalued currency.

\section{Discussion and Results}

From the descriptive statistics results expressed per Swiss Franc in Table 1-Table 5, it is clear from the tail behaviour, skewness and kurtosis, that there are strong signs of pegging.

The tail behaviour of the Euro and a number of currencies particularly in Europe exhibit similar behaviour. The Danish Krone, Bulgarian Lev and West African Franc mimic the behaviour of the Euro almost perfectly. Moving on to the US Dollar, the American, African and Asian currencies tend to peg to the Dollar, particularly Middle East currencies like the Omani Rial follow the US Dollar very closely. The descriptive statistics do not reveal significant evidence that currencies included in the sample are pegged to the Japanese Yen and British Pound.

The $+/-2.5 \%$ band is constructed for each of the currencies to determine the probabilities that the jumps stay within the band against the chosen anchors. Table 6 shows the results for some of the currencies against the anchors. Figure 6 shows the idea behind the bands 
for the Danish Krone and Ukrainian Hryvnia against the Euro. The red lines indicate the upper and lower bounds. It is evident that for the Danish Krone, the jumps are $100 \%$ of the time within the band compared to the Ukrainian Hryvnia with a probability of $65.351 \%$.

Regressions are run for the local currencies against the candidate anchors as shown in Table 7-Table 11, clearly showing all the currencies by continent. The regressions clearly bring out the results obtained from the descriptive statistics, showing the preferred anchor per currency in the sample. Countries in Europe, with the exception of Armenia and Ukraine, attach a much higher weight to the Euro compared to the other candidate anchor currencies. This same analogy applies to Oceania, with the exception of Fiji. Moving on to the other continents, the US Dollar is predominantly the preferred anchor currency in Africa, Americas and Asia. Africa, however, has a great Euro preference in the West and Central regions that anchor their Franc currency to the Euro. In addition to this, the periphery North Africa and South Africa countries namely Tunisia, Morocco and South Africa attach a higher weight to the Euro too. These regression results are robust and remain more or less the same when the numeraire is changed to the New Zealand Dollar.

Figure 7 shows a summary of the distribution of the two preferred anchor currencies across the globe. Generally, most countries prefer to peg to a basket of currencies (Dollar and Euro) rather than peg to a single currency.

Table 12 and Table 13 show some of the responses of currencies in the sample to the market pressure variable. This variable is statistically significant for some countries but rather with a low magnitude in value.

Table 14, Table 15 and Table 16 show the switching behaviour among anchor currencies over 3 sub-periods for the Norwegian Krone, Hong Kong Dollar and Colombian Peso. Regressions of the type from Table 12-Table 16 are important in the application of our regime classification algorithm.

Using the proposed algorithm in Figure 5, we are able to classify the regimes being practised by monetary authorities into 5 different categories shown in Figure 8.

We find rather uninteresting results for strictly pegged regimes particularly from the Gulf and the Middle East region whose regression results produce perfect pegs to the US Dollar, a weight of 1 indicating that they are exactly tracking the US Dollar. The same regression result apples to the West and Central African Franc that is strictly pegged to the Euro. The Pound Sterling and Japanese Yen are rather unpopular, only a single currency, the Seychellois Rupee attaches a higher weight to the Pound Sterling compared to other candidate anchors.

All de jure peggers turned out to be de facto peggers showing that there is no fear of pegging but rather a fear of floating as a number of floaters somewhat turned out to be peggers to some extent. A comparison of a sample of the results is indicated in Table 17.

As seen in Figure 9, pegs formed the biggest proportion of the sample while floats only took a small share. The only hyper float in the sample turned out to be the Argentine Peso and this is no surprise given the high inflation rates registered in the country over the recent years, this is rather a dysfunctional economy. 
We go further and ask ourselves whether the Bretton Woods period really mattered. The Bretton Woods period is defined as one characterised by US Dollar pegging, and the US Dollar was further pegged to Gold. To do this, we use the French Franc as the local currency and run the regression in equation 1 using the Deutschmark (DM) as a proxy for the Euro. The data is also split into the Bretton Woods period and post-Bretton Woods period. The Bretton Woods period is characterised by a high weight attached to the US Dollar and then there is a switch from the US Dollar to the DM in the postBretton Woods period. This is shown in Table 18. In addition, the graphs in Figure 10 shows the exchange rate relationship between four currencies and the US Dollar, splitting the periods into three, the Bretton Woods and the post-Bretton Woods period which includes the Euro period. There is pictorial evidence that indicates a regime shift from the fixed to floating period. This result is further re-enforced by the exchange rate volatility graphs shown in Figure 11, there is more volatility in the post-Bretton Woods period, one characterised by floating.

Figure 12 and Figure 13 show the change in reserves held by the Euro area, Ukraine, Bulgaria and Norway in US Dollars. There is a theoretical grounding that more volatility in reserves implies more intervention in the financial markets by monetary authorities to defend an exchange rate regime, indicating that this regime could be a fixed type and less volatility implies less intervention and thus the regime is more inclined to be a floating type. Figure 13, shows to a greater extent that our results are consistent with the theoretical grounding. The behaviour of Ukraine's reserves which is classified by the algorithm as a free float is behaving more like the Euro area that is a de jure float. Bulgaria and Norway that are classified as hard pegs are behaving exactly as pegs should be, this is consistent with the algorithm classification.

Figure 14 simply shows how the emerging markets have been tracking the inflation of the advanced economies over time. There has been significant drop in inflation rates of emerging markets and this could probably be attributed to currency pegging by emerging market economies.

\section{Conclusion}

This paper investigates the de jure and de facto exchange rate regimes being practised by a number of monetary policy authorities using data extracted from the IMF database spanning mostly the period 2000-2018. This investigation developed an algorithm that adopts a regression and within the band approach to classify an exchange rate regime. It is our belief that the algorithm performs quite well despite the fact that some shortcomings may be identified including among others that it might be hard to identify basket pegs though the regressions to a greater extent try to solve this weakness. Findings show that there is indeed a difference between the de jure and de facto regimes, however, there is more evidence of fear of floating than fear of pegging as first sighted by Calvo and Reinhart (2002). There also seems to be a major preference for particular anchor currencies within different regions, re-enforcing the findings of Eichengreen (2011), with the Euro being predominantly preferred in Europe, some parts of Africa and Oceania while the US Dollar, the rest of the world with strictly pegged regimes in the Gulf and the Middle East region that exactly track the US Dollar, essentially eliminating volatility against this particular anchor currency. There is also evidence of some authorities preferring a 1:1 parity with their anchor currency of choice. From this paper, 
it is evident that currencies like the British Pound and Japanese Yen have lost popularity over the years especially with the emergence of the Euro and the unity that comes with it. In conclusion, we find that most countries are inclined towards a pegged regime with over $70 \%$ in the sample practising some kind of pegged regime.

\section{References}

Adam, C. \& Cobham, D. 2007. Exchange Rate Regimes and Trade. Manchester School, 75, 44-63.

Aghion, P., Bacchetta, P. \& Banerjee, A. 2001. Currency crises and monetary policy in an economy with credit constraints. European economic review, 45, 1121-1150.

Aristotelous, K. 2001. Exchange-Rate Volatility, Exchange-Rate Regime, and Trade Volume: Evidence from the UK-US Export Function (1889-1999). Economics Letters, 72, 87-94.

Bacchetta, P. \& Van Wincoop, E. 2000. Does Exchange-Rate Stability Increase Trade and Welfare? American Economic Review, 90, 1093-1109.

Baig, M. T. 2001. Characterizing exchange rate regimes in post-crisis East Asia, International Monetary Fund.

Bayoumi, T. \& Eichengreen, B. 1998. Exchange rate volatility and intervention: implications of the theory of optimum currency areas. Journal of International Economics, 45, 191-209.

Bordo, M. D. 2003. Exchange rate regime choice in historical perspective. National Bureau of Economic Research.

Calvo, G. A. \& Mishkin, F. S. 2003. The mirage of exchange rate regimes for emerging market countries. Journal of Economic Perspectives, 17, 99-118.

Calvo, G. A. \& Reinhart, C. M. 2002. Fear of floating. The Quarterly Journal of Economics, 117, $379-408$.

Chang, R. \& Velasco, A. 2000. Financial fragility and the exchange rate regime. Journal of economic theory, 92, 1-34.

Eichengreen, B. 2011. Exorbitant Privilege: The rise and fall of the Dollar and the Future of the International Monetary System, Oxford University Press.

Fleming, J. M. 1971. On exchange rate unification. the economic Journal, 81, 467-488.

Frankel, J. \& WEI, S.-J. 2008. Estimation of de facto exchange rate regimes: Synthesis of the techniques for inferring flexibility and basket weights. IMF staff papers, 55, 384-416.

Frankel, J. A. 1992. Is Japan creating a yen bloc in East Asia and the Pacific? National bureau of economic research.

Frankel, J. A. 1999. No single currency regime is right for all countries or at all times. National Bureau of Economic Research.

Frankel, J. A. \& Wei, S.-J. 1994. Yen bloc or dollar bloc? Exchange rate policies of the East Asian economies. Macroeconomic Linkage: Savings, Exchange Rates, and Capital Flows, NBER-EASE Volume 3. University of Chicago Press.

Ghosh, A. R., Gulde, A.-M., Ostry, J. D. \& Wolf, H. C. 1997. Does the nominal exchange rate regime matter? National Bureau of Economic Research.

Ghosh, A. R., Ostry, J. D. \& Qureshi, M. S. 2015. Exchange rate management and crisis susceptibility: A reassessment. IMF Economic Review, 63, 238-276. 


\section{Vol. 5 Issue: 1/ April 2020}

Haile, F. D. \& POZO, S. 2006. Exchange rate regimes and currency crises: an evaluation using extreme value theory. Review of International Economics, 14, 554-570.

Ilzetski, E., Reinhart, C. M. \& Rogoff, K. S. 2017. Exchange arrangements entering the 21st century: Which anchor will hold? National Bureau of Economic Research.

Kawai, M. \& Akiyama, S. 1998. The role of nominal anchor currencies in exchange rate arrangements. Journal of the Japanese and International Economies, 12, 334-387.

Kenen, P. B. \& Rodrik, D. 1986. Measuring and Analysing the Effects of Short-term Volatility in Real Exchange Rates. Review of Economics and Statistics, 68, 311-315.

Klein, M. W. \& Shambaugh, J. C. 2012. Exchange rate regimes in the modern era, MIT Press.

Krugman, P. R. 1991. Target Zones and Exchange Rate Dynamics. The Quarterly journal of economics, 106, 669-682.

Levy-Yeyati, E. \& Sturzenegger, F. 2005. Classifying exchange rate regimes: Deeds vs. words. European economic review, 49, 1603-1635.

Levy-Yeyati, E. \& Sturzenegger, F. 2016. Classifying exchange rate regimes: 15 years later.

Mckinnon, R. I. 2000. The East Asian dollar standard, life after death? Economic Notes, 29, 31-82.

Mishkin, F. S. 2004. Can Inflation Targeting Work in Emerging Market Countries? National Bureau of Economic Research, Inc., NBER Working Papers: 10646.

Mundell, R. A. 1961. A theory of optimum currency areas. The American economic review, 51, 657-665.

Mussa, M. Nominal exchange rate regimes and the behaviour of real exchange rates: Evidence and implications. 1986. Elsevier, 117-214.

Obstfeld, M. \& Rogoff, K. 1995. The mirage of fixed exchange rates. Journal of Economic perspectives, 9, 73-96.

Ohno, K. 1999. Exchange rate management in developing Asia: Reassessment of the pre-crisis soft dollar zone. ADBI Research Paper Series.

Reinhard, C. M. \& Rogoff, K. S. 2004. The modern history of exchange rate arrangements: a reinterpretation. the Quarterly Journal of economics, 119, 1-48.

Ricci, L. A. 2008. A model of an optimum currency area. Economics: The Open-Access, OpenAssessment E-Journal, 2, 8.

Rose, A. K. 2000. One money, one market: the effect of common currencies on trade. Economic policy, 15 .

Schnabl, G. 2003. De jure versus de facto Exchange Rate Stabilization in Central and Eastern Europe. Tubingen University Economics \& Business Administration Working Paper.

Shambaugh, J. C. 2004. The effect of fixed exchange rates on monetary policy. The Quarterly Journal of Economics, 119, 301-352.

Svensson, L. E. O. 1992. An Interpretation of Recent Research on Exchange Rate Target Zones. The Journal of economic perspectives, 6, 119-144. 
